\title{
Multipliers for deflections in reinforced concrete flat slabs
}

\author{
R. L Vollum* \\ Imperial College
}

Ideally, slab deflections should be calculated using non-linear cracked section analysis. In practice, slabs are often designed using elastic finite element analysis and deflections are estimated using a reduced elastic modulus for the concrete. This paper examines the problem of determining an equivalent elastic modulus that accounts for the increase in deflection due to cracking, shrinkage and creep. A method is proposed for estimating long-term deflections in flat slabs by increasing elastic deflections with multipliers derived from analysis of equivalent beam strips. Deflections in flat slabs are usually governed by cracking during construction in which case deflection multipliers are almost independent of the permanent design load under which EC2 requires deflections to be calculated. In this case, it is shown that cracking and shrinkage increase long-term deflection multipliers for flat slabs by a factor of approximately two.

\begin{tabular}{|c|c|}
\hline Notation & \\
\hline$a$ & deflection \\
\hline$f_{c m}$ & mean concrete cylinder strength at time $t$ \\
\hline$f_{c t}$ & indirect concrete tensile strength \\
\hline$f_{\text {ctmodified }}$ & $\begin{array}{l}\text { modified concrete tensile strength used to } \\
\text { account for construction loading in } \\
\text { deflection calculations }\end{array}$ \\
\hline$f_{\text {ckeff }}$ & concrete compressive strength \\
\hline & $\begin{array}{l}\text { corresponding to } f_{\text {ctmodified }} \text { proposed for } \\
\text { use in EC2 span to depth formulae }\end{array}$ \\
\hline C & $\begin{array}{l}\text { long-term deflection or curvature } \\
\text { multiplier due to cracking and shrinkage }\end{array}$ \\
\hline$E_{c}$ & concrete elastic modulus \\
\hline$E_{\text {composite }}$ & $\begin{array}{l}\text { equivalent concrete effective modulus } \\
\text { used to account for differences in loading } \\
\text { ages }\end{array}$ \\
\hline$E_{c(p e a k-4)}$ & $\begin{array}{l}\text { concrete elastic modulus four days before } \\
\text { application of } w_{\text {peak }}\end{array}$ \\
\hline$E_{c s t r}$ & concrete elastic modulus at striking \\
\hline$K, K_{m i}$ & $\begin{array}{l}\text { damage parameter (where min denotes } \\
\text { minimum value for member) }\end{array}$ \\
\hline$M_{r}$ & cracking moment \\
\hline
\end{tabular}

\footnotetext{
* Department of Civil and Environmental Engineering, Imperial College Road, Imperial College, London SW7 2BU, UK.
}

(MCR 1000) Paper received 3 January 2002; last revised 15 May 2002; accepted 22 July 2002

\begin{tabular}{|c|c|}
\hline$w_{i}$ & design imposed load \\
\hline$w_{\text {perm }}$ & permanent load \\
\hline$w_{\text {peak }}$ & peak construction load \\
\hline$w_{\text {strike }}$ & load at striking \\
\hline$\beta$ & $\begin{array}{l}\text { coefficient in interpolation coefficient } \\
\text { used to find mean curvature }\end{array}$ \\
\hline$\delta$ & $\begin{array}{l}\text { moment after redistribution/elastic } \\
\text { moment }\end{array}$ \\
\hline$\phi$ & creep coefficient \\
\hline$\phi_{\text {eff }}$ & $\begin{array}{l}\text { equivalent creep coefficient used to } \\
\text { account for different loading ages }\end{array}$ \\
\hline $\begin{array}{l}\phi_{E C 2} \\
\zeta\end{array}$ & $\begin{array}{l}\phi_{E C 2}=\phi E_{c 28} / E_{c} \\
\text { interpolation coefficient used to find } \\
\text { mean curvature } 1 / r_{m}\end{array}$ \\
\hline
\end{tabular}

\section{Introduction}

Predictions of deflections in two-way spanning slabs are best made with finite element programs capable of cracked section analysis that are not widely used. In practice, slabs are commonly designed using elastic finite analysis. Designers frequently estimate long-term deflections using a reduced concrete elastic modulus in an elastic finite element analysis. The reduced concrete elastic modulus needs to account for the increase in deflection due to cracking, creep and shrinkage. CIRIA Report R110 ${ }^{1}$ suggests that long-term slab deflections can be estimated using an equivalent elastic modulus 
equal to $0 \cdot 5 E_{c} /(1+\phi)$. This paper reviews this recommendation in the light of new design recommendations $^{2,3}$ based on test data from Cardington. ${ }^{4}$

This paper also demonstrates that it is unnecessary to carry out non-linear finite element analysis to make realistic estimates of deflections in flat slabs. It is proposed that long-term deflections are calculated by increasing instantaneous deflections in uncracked slabs by a multiplier. Deflection multipliers depend on the increase in curvature due to cracking, creep and shrinkage which in turn depend on: (a) material properties; (b) the ratio of applied load to cracking load; (c) reinforcement; and $(d)$ structural arrangement. The interaction of these effects is complex and not readily encapsulated in a simple formula. Two approaches are proposed for the evaluation of deflection multipliers. In the first method, deflection multipliers are obtained from the analysis of equivalent beam strips. The second method is based on the observation that long-term deflections in flat slabs are usually governed by cracking under the peak construction load. In this case, it is possible to make simplifying assumptions since deflection multipliers are almost independent of the design permanent load under which deflections are calculated.

\section{Methodology used for calculation of deflection}

Deflections are calculated in this article, using the method given in $\mathrm{MC}^{5} 0^{5}$ and $\mathrm{EC} 2^{6}$ in which mean curvatures are derived as follows

$$
1 / r_{m}=\zeta\left(1 / r_{2}+1 / r_{s h 2}\right)+(1-\zeta)\left(1 / r_{1}+1 / r_{s h 1}\right)
$$

where $1 / r=M / E_{c} I$ for states 1 and 2 and

$$
\zeta=1-\beta\left(M_{r} / M\right)^{2} \text { for } M \geqslant \sqrt{\beta} M_{r}
$$

The author ${ }^{3}$ has previously suggested that $\beta$ should usually be taken as 0.5 since tension stiffening is lost rapidly and the duration of peak loads is generally uncertain. Equation (2) is valid for $M \geqslant \sqrt{\beta} M_{r}$ in this article and $\mathrm{MC} 90^{5}$ but for $M \geqslant M_{r}$ in EC2. ${ }^{6}$ The author prefers the MC90 formulation for reasons discussed previously. ${ }^{3} 1 / r_{s h}$ is the shrinkage curvature. Material properties were derived in this article using EC2 with the following modifications. In this paper, the creep coefficient $\phi$ is defined as

$$
\phi=\varepsilon / \varepsilon_{i}-1
$$

where $\varepsilon$ is the long-term strain and $\varepsilon_{i}$ is the instantaneous strain at loading $\sigma / E_{c}$ where $E_{c}$ is the elastic modulus at loading. In EC2, creep coefficients $\phi$ are scaled by $E_{c 28} / E_{c}$ to give $\phi_{E C 2}$ where $E_{c 28}$ is the elastic modulus at 28 days. Therefore, all creep coefficients quoted in this paper equal $\phi_{E C 2} E_{c} / E_{c 28}$. The equation given in EC2 to calculate concrete tensile strength was modified as follows

$$
f_{c t m}=0 \cdot 3 f_{c m}^{\prime(2 / 3)}
$$

The mean concrete cylinder strength $f_{\mathrm{cm}}^{\prime}$ at time $t$ was used in equation (4), unless stated otherwise, rather than the characteristic strength $f_{c k}$ used in EC2 for reasons discussed previously. ${ }^{3}$

\section{Multipliers for deriving long-term deflections}

Cracking and shrinkage deflection multipliers were defined as

$$
C=a_{\text {long }} /\left[a_{i}(1+\phi)\right]
$$

where $a$ is deflection. Instantaneous deflections $a_{i}$ were derived using the gross concrete section, neglecting reinforcement, and the concrete elastic modulus at first loading.

The influences on curvature multipliers $C$ (defined similarly to deflection multipliers) of creep, $M / M_{r}$, concrete tensile strength and reinforcement index $A_{S} / b d$ were investigated for a section at mid-span of the $250 \mathrm{~mm}$ thick slab shown in Fig. 1. The concrete cylinder strength was taken as $30 \mathrm{MPa}$ and the slab was first loaded at 3 days to simulate early age striking. Concrete material properties including strength development were calculated in accordance with EC2 assuming normal strength concrete. Fig. 2 shows the relationship between long-term curvature multipliers and $M / M_{r}$ for various values of $A_{s} / b d$. EC2 recommends that long-term deflections should be calculated under the quasi-permanent load which is taken as $0 \cdot 3 w_{i}$ for offices. Analysis shows that the total permanent load $w_{\text {perm }}$ corresponding to an imposed load of $0 \cdot 3 w_{i}$ typically varies between $0.5 w_{u}$ and $0.6 w_{u}$ where $w_{u}$ is the design ultimate load. Therefore, the effects on curvature multipliers of varying $A_{s} / b d$ (see Fig. 3) were investigated for $w_{\text {perm }} / w_{u}=0.6$ with the concrete tensile strength varying between $2 \cdot 41 \mathrm{MPa}$ (at 3 days) and $3.39 \mathrm{MPa}$ (at 28 days). Fig. 3 shows that curvature multipliers are sensitive to concrete tensile strength at low values of $A_{s} / b d$ (i.e. in slabs). Fig. 4 shows that the curvature multiplier $C$ reduces with increasing creep coefficient $\phi$ since the mean curvature is not proportional to $1+\phi$.

BS $8110^{7}$ states that deflections can be calculated using the equation

$$
a=k l^{2}\left(1 / r_{m}\right)
$$

where $1 / r_{m}$ is the curvature derived from the maximum elastic bending moment in the span for continuous or simply supported beams. The coefficient $k$ depends on the shape of the bending moment diagram. Equation (6) implies long-term deflection multipliers can be derived from analysis of the section at the maximum span moment. This was investigated for the propped cantile- 


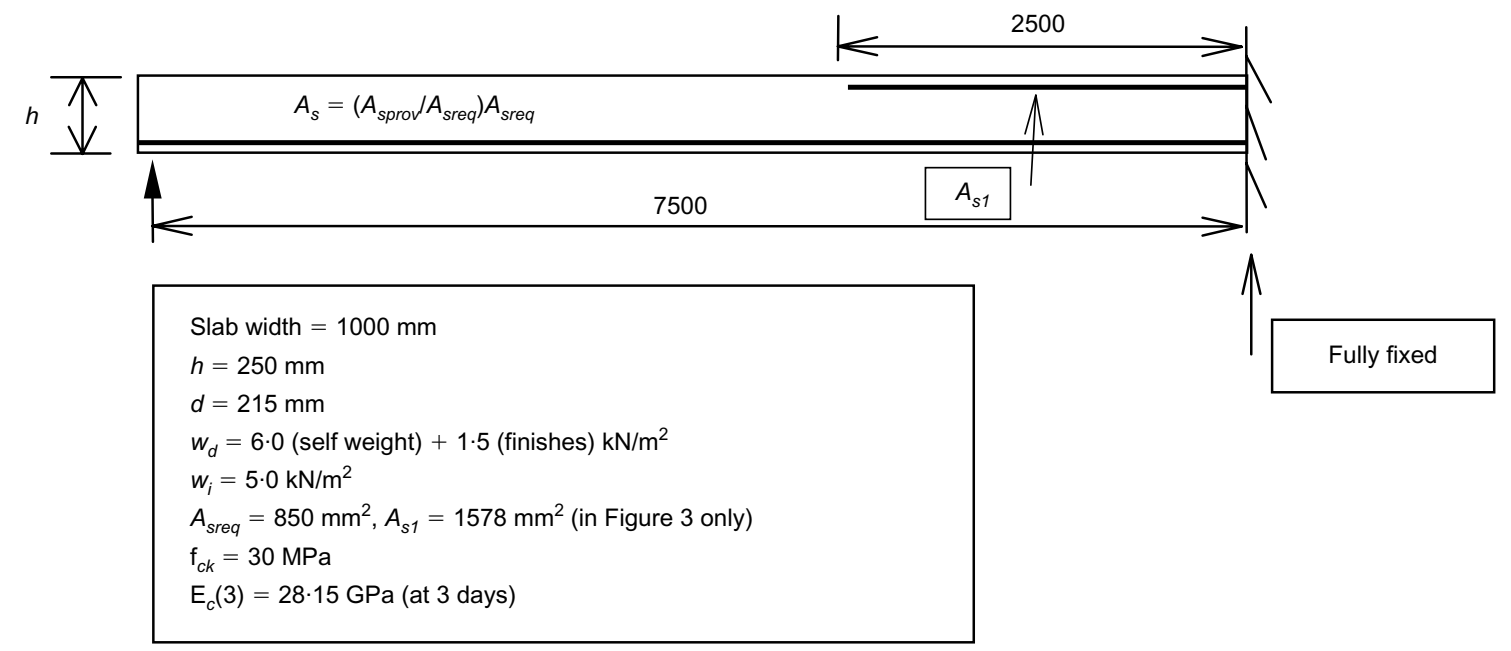

Fig. 1. Details of slab and loading used in parametric study

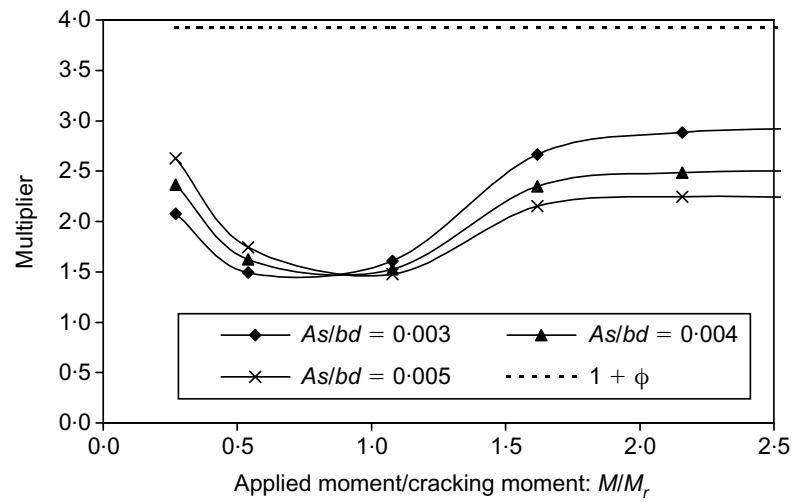

Fig. 2. Curvature multipliers vs. $M / M_{r}$

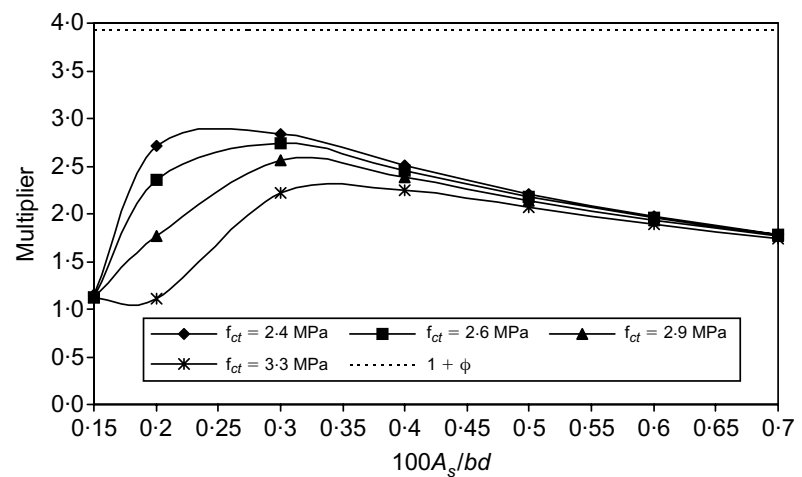

Fig. 3. Curvature multipliers vs. $A_{s} / b d$ with $M=0 \cdot 6 M_{u}$

ver shown in Fig. 1 for which 10000 day deflection multipliers $C$ were derived as follows.

M1. numerical integration of curvatures and application of boundary constraints.

M2. numerical integration of curvatures derived from elastic moments.

M3. Equation (6).

Magazine of Concrete Research, 2003, 55, No. 2

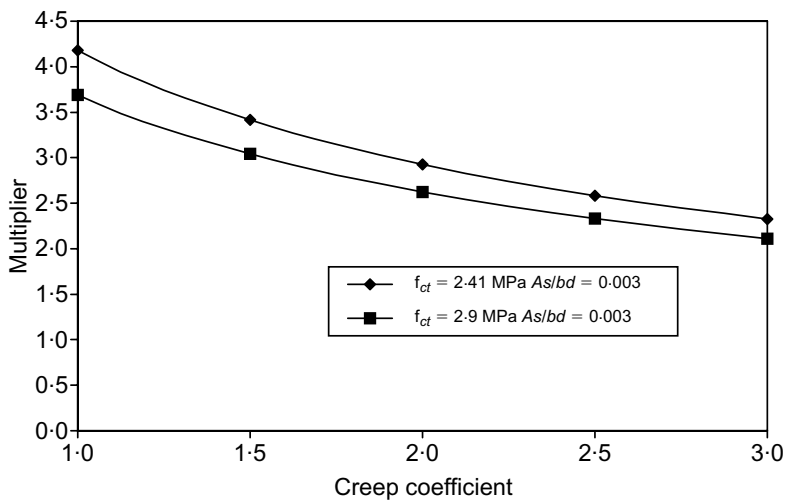

Fig. 4. Curvature multipliers vs. $\phi M=0 \cdot 6 M_{u}$

The results are shown in Fig. 5 that shows that methods 2 and 3 gave poor estimates of deflection since the maximum span moment was less than given by elastic analysis. The moments within a cracked statically determinate member depend on the distribution of rein-

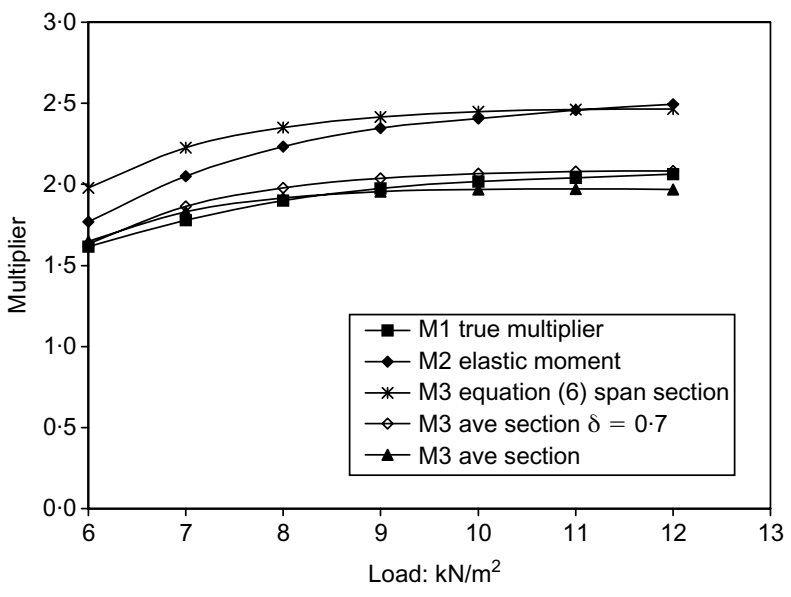

Fig. 5. Deflection multiplier vs. load 
forcement between the span and supports. This was investigated for the propped cantilever shown in Fig. 1. Maximum deflections under $w_{\text {perm }}=9 \mathrm{kN} / \mathrm{m}^{2}$ are plotted in Fig. 6 against the factor $\delta$ used to reduce the elastic moment at the supports in order to obtain the design moment. All the slabs considered in Fig. 6 had the same collapse load but varying reinforcement arrangements. Deflections were calculated using methods 1 and 2 above. Figure $2 b$ shows that method 2 is reasonably accurate if $\delta=0.7$ when almost the same tension reinforcement is provided in the span and supports and bending moments are closest to elastic moments. It follows that a partial fix for methods 2 and 3 is to calculate curvatures for an equivalent member with equal areas of tension steel in the span and at continuous supports. Method 3 gives good estimates of deflection if curvatures are calculated using the average of the section properties at mid-span and continuous supports with $\delta$ chosen to give equal areas of tension steel in the span and at continuous supports (see 'M3 average section $\delta=0.7$ ' in Fig. 6). Deflections are slightly underestimated if curvatures are calculated with the average of the section properties at mid-span and continuous supports corresponding to elastic design moments (see 'M3 average section' in Fig. 5). In all cases, the actual section properties in the span were used to calculate the cracking moment in equation (6).

\section{Influence of construction loading}

The author has previously proposed ${ }^{3,4}$ that a modified concrete tensile strength is used in deflection calculations to take account of cracking under construction loading. The modified concrete tensile strength $f_{\text {ctmodified }}$ is taken as

$$
f_{\text {ctmodified }}=K_{\min } w / \sqrt{\beta}
$$

where $K_{\text {min }}$ is the minimum value of $K=\sqrt{\beta} f_{c t} / w$ evaluated at striking, peak construction load and full service load. Procedures for calculating peak construction loads are discussed in detail by Beeby. ${ }^{8}$ In this

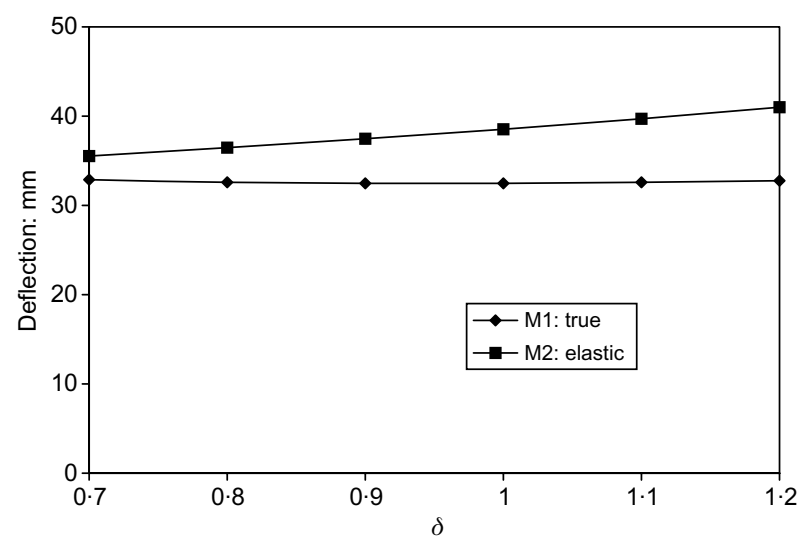

Fig. 6. Deflections under $w_{\text {perm }}$ vs. $\delta$ paper, as previously, ${ }^{3}$ the peak construction load was taken as

$$
w_{\text {peak }}=w_{\text {self }}+0 \cdot 7\left(w_{\text {self }}+w_{\text {con }}\right)
$$

where $w_{c o n}$ is a construction load which was taken as $0.75 \mathrm{kN} / \mathrm{m}^{2}$. Differences in loading ages were taken into account using an equivalent concrete effective modulus $E_{\text {composite }}$ which was derived in accordance with Webster's suggestion as follows

$$
E_{\text {composite }}=\Sigma \Delta w_{\mathrm{i}} / \Sigma\left(\Delta w_{\mathrm{i}} / E_{\text {ceffi }}\right)
$$

where $E_{c e f f i}=E_{c} /\left(1+\phi_{i}\right)$ and $i$ denotes the load increment $\Delta w_{i}$. The creep coefficient corresponding to $E_{\text {composite }}$ is defined in this paper as

$$
\phi_{\text {eff }}=\left(E_{\text {cstrike }} / E_{\text {composite }}\right)-1
$$

The effect of construction loading on deflection multipliers $C$ is shown in Fig. 7 for $(a)$ the slab in Fig. 1 and (b) a slab similar to that in Fig. 1 with the simple support replaced by a wall with rotational stiffness, per $7.5 \mathrm{~m}$ width, equal to a $400 \times 250$ column with its minor axis oriented parallel to the slab edge. Points of contraflexure were assumed at midheight of the column $1750 \mathrm{~mm}$ above and below the centreline of the slab. The reinforcement in the slab of the sub-frame was designed for elastic design ultimate moments assuming equal elastic moduli for the concrete in the column and slab. Slabs were struck at 3 days, the peak construction load was applied at 7 days and the superimposed dead load was applied at 60 days. Concrete properties were calculated in accordance with EC2. Deflections were calculated by integration (method 1) using $f_{\text {ctmodified }}$ and $E_{\text {composite }} . K_{\text {peak }}$ was critical in all cases. Instantaneous elastic deflections in the sub-frame were calculated using the elastic modulus in the slab at striking for both the slab and column. Long-term deflections in the sub-frame were calculated with long-term elastic moduli in the column of (a) $10 \mathrm{kN} / \mathrm{mm}^{2}$ and $(b)$ $20 \mathrm{kN} / \mathrm{mm}^{2}$. The column was assumed to be uncracked. Fig. 7 shows that multipliers are $(a)$ relatively

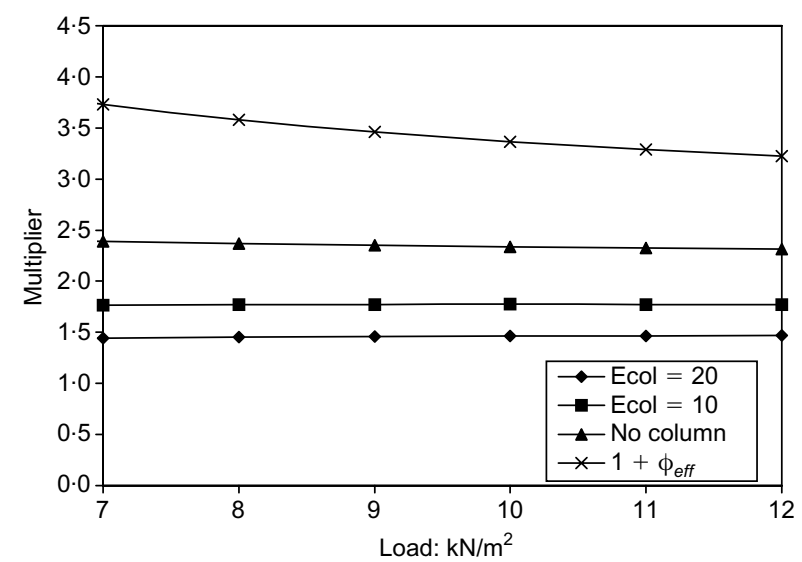

Fig. 7. Influence of construction loading and columns on multiplier

Magazine of Concrete Research, 2003, 55, No. 2 


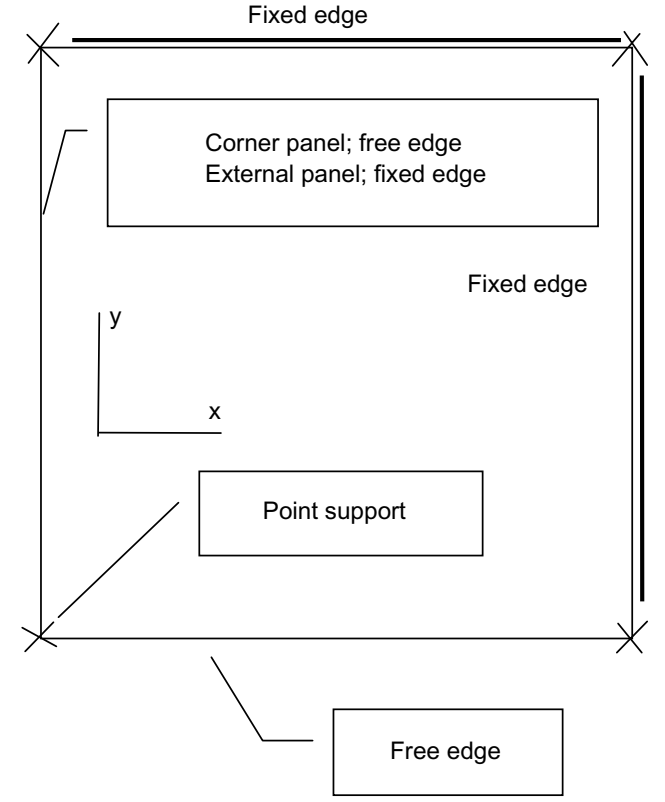

Fig. 8. Panels used in parametric studies for multipliers

insensitive to $w_{\text {perm }}$ for the assumed load history and (b) depend on the stiffness of columns. Deflection multipliers $C$ are significantly smaller for the slab with the column than for the propped cantilever since $(a)$ continuity at the column reduces the span moment and (b) long-term column moments are greater than instantaneous column moments since the slab stiffness reduces more than the column stiffness.

\section{Multipliers for deflections in flat slabs}

Ten year deflection multipliers were calculated for the flat slabs shown in Fig. 8 (which gives details of the reinforcement and loading) using Hossain's ${ }^{2}$ finite element program. Deflection multipliers depend on slab edge boundary conditions and panel aspect ratio. To account for this, multipliers were estimated for beam strips spanning in the $x$ and $y$ directions with the average of the reinforcement in the column and middle strips. The multipliers in the $x$ and $y$ directions $\left(C_{x}\right.$ and $\left.C_{y}\right)$ were combined as follows to give an overall multiplier

$$
C=\left(C_{x}+\alpha C_{y}\right) /(1+\alpha)
$$

where $\alpha=a_{y} / a_{x}$ where $a_{x}$ and $a_{y}$ are maximum elastic deflections in beam strips spanning in the $x$ and $y$ directions respectively. Multipliers corresponding to plate analysis, $C_{x}, C_{y}$ and $C$ are plotted in Fig. 9 for C30 concrete. In practice, equation (11) is considered unnecessarily complex and it is recommended that the maximum of $C_{x}$ and $C_{y}$ is used as an estimate of $C$.

\section{Multipliers for deflections in flat slabs with multiple panels}

This section investigates deflection multipliers in a series of slabs analysed by Vollum and Hossain ${ }^{3}$ pre-

\section{Slab details}

$7 \cdot 5 \mathrm{~m}$ square; supported on points at each corner.

Rotational restraint as shown in figure.

Bar diameter $=16 \mathrm{~mm}$

Dead load $0.024 \times$ (thickness in $\mathrm{mm}$ )

Permanent superimposed load $3 \mathrm{kN} / \mathrm{m}^{2}$

$f_{c t}=2.9 \mathrm{MPa}$

$E_{c}=32 \mathrm{GPa}$

Reinforcement divided between column and middle

strips in accordance with BS 8110.

One fixed edge; ave steel $\left(\mathrm{mm}^{2} / \mathrm{m}\right) 907$ top,

708 bottom

Two fixed edges; ave steel 694 top, 556 bottom viously. The author ${ }^{3}$ previously calculated deflections in a large number of flat slabs consisting of nine square bays arranged in a square using Hossain's finite element program. ${ }^{2}$ The slabs were designed using an equivalent frame in accordance with EC2 taking pattern loading into account. Details of the slabs considered in this study are given in Table 1 and Figs 11-16. Slab thicknesses in Figs 12-14 and 16 and were determined using the EC2 span to depth rules using a reduced concrete compressive strength $f_{\text {ckeff }}$ to account for the effect of construction loading. The author ${ }^{3}$ has given the derivation and background to $f_{\text {ckeff }}$ previously. Unless noted otherwise, the slabs considered in this article (see Table 1) were struck at 3 days, the peak construction load was applied at 7 days, a superimposed dead load of $1.5 \mathrm{kN} / \mathrm{m}^{2}$ was applied at 60 days and the quasi-permanent load of $0.3 w_{i}$ was applied at one year with $f_{c k}=30 \mathrm{MPa}, A_{\text {sprov }}=A_{\text {sreq }}$ and $w_{i}=$ $2.5 \mathrm{kN} / \mathrm{m}^{2}$. Deflections were calculated under $w_{\text {perm }}$ using $f_{\text {ctmodified }}$ and $E_{\text {composite }}$. Material properties were derived using EC2 as described previously. The longterm effective elastic modulus in the columns was taken as $10 \mathrm{kN} / \mathrm{mm}^{2}$ unless noted otherwise. Deflection multipliers were derived from $(a)$ non-linear finite element (NLFE) analysis (see Vollum and Hossain $^{3}$ for details) and (b) analysis of an equivalent subframe (see Fig. 10) in which the average of the reinforcement in the column and middle strips was used. The main difficulty was to determine the edge column moment to be used in the subframe analysis. Deflection multipliers were significantly overestimated if columns were excluded from the analysis but underestimated if the edge column moment was calculated in the sub-frame analysis. The latter is demonstrated in Fig. 11 which 
Table 1. Slab details in Figure 7

\begin{tabular}{l|c|c|c|c|c|c}
\hline Fig. & $\begin{array}{c}\text { Span: } \\
(\mathrm{m})\end{array}$ & $\begin{array}{c}\text { Slab thickness } \mathrm{h}: \\
(\mathrm{mm})\end{array}$ & $\begin{array}{c}\text { Column size } \\
\text { multiplier: } \mathrm{M}^{\#}\end{array}$ & $A_{\text {sprov }} / A_{\text {sreq }}$ & $\begin{array}{c}f_{c k} \\
(\mathrm{MPa})\end{array}$ & $\begin{array}{c}w_{i} \\
\left(\mathrm{kN} / \mathrm{m}^{2}\right)\end{array}$ \\
\hline 11 & $7 \cdot 5$ & 265 & $0 \cdot 75$ & 1 & 30 & $2 \cdot 5$ \\
11 & $7 \cdot 5$ & 265 & 1 & 1 & 30 & $2 \cdot 5$ \\
11 & $7 \cdot 5$ & 265 & $1 \cdot 5$ & 1 & 30 & $2 \cdot 5$ \\
12 & $7 \cdot 5$ & 265 & 1 & 1 & 30 & $2 \cdot 5$ \\
12 & $7 \cdot 5$ & 244 & 1 & 1 & 40 & $2 \cdot 5$ \\
12 & $7 \cdot 5$ & 227 & 1 & 1 & 30 & $2 \cdot 5$ \\
13 & $7 \cdot 5$ & 265 & 1 & 1 & 30 & see Fig 13 \\
14 & $7 \cdot 5$ & 265 & 1 & $1 \cdot 1$ & 30 & $2 \cdot 5$ \\
14 & $7 \cdot 5$ & 255 & 1 & $1 \cdot 3$ & 30 & $2 \cdot 5$ \\
14 & $7 \cdot 5$ & 238 & 1 & $1 \cdot 5$ & 30 & $2 \cdot 5$ \\
14 & $7 \cdot 5$ & 224 & 1 & 1 & 30 & $2 \cdot 5$ \\
16 & $7 \cdot 5$ & 265 & 1 & 1 & 30 & $2 \cdot 5$ \\
16 & $8 \cdot 25$ & 302 & 1 & 1 & 30 & $2 \cdot 5$ \\
16 & $9 \cdot 0$ & 348 & 1 & 10 & $2 \cdot 5$ \\
\hline
\end{tabular}

\# Basic column sizes were as follows: Internal 400 square, external 400 by 250 and corner $281 \mathrm{~mm}$ square. Column side length $=M^{*}$ (basic size). Floor to floor height was $3.5 \mathrm{~m}$.

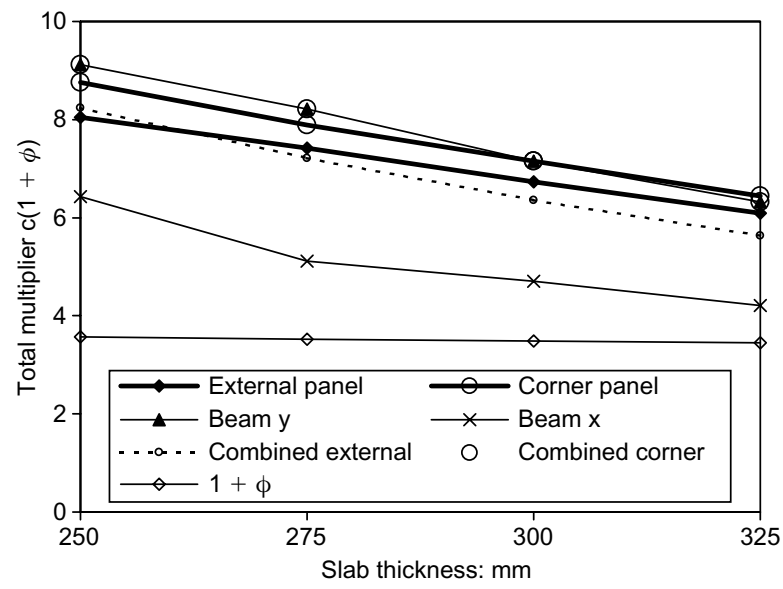

Fig. 9. 10-year deflection multipliers vs. slab thickness for panels $C 30$

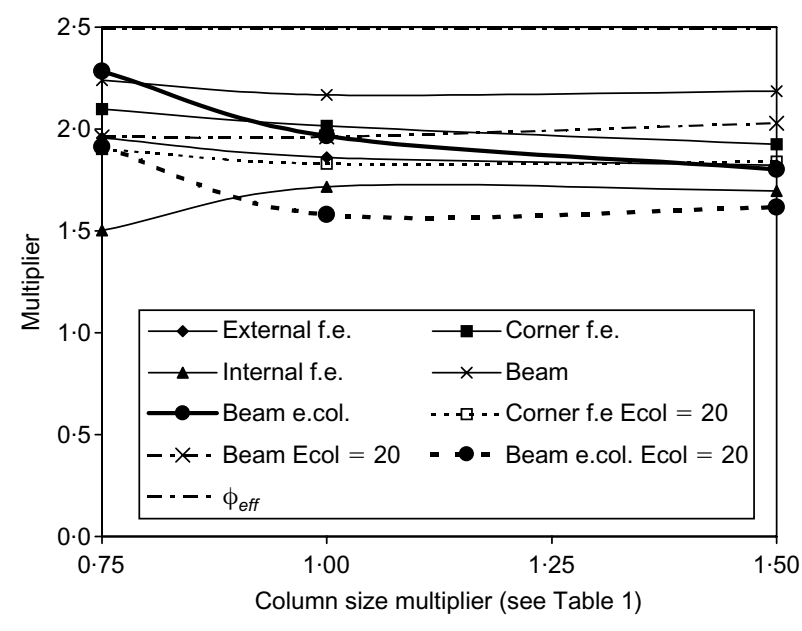

Fig. 11. Deflection multipliers vs. column size (h slab $=265 \mathrm{~mm} ; E_{c o l}=10$ unless, shown otherwise)

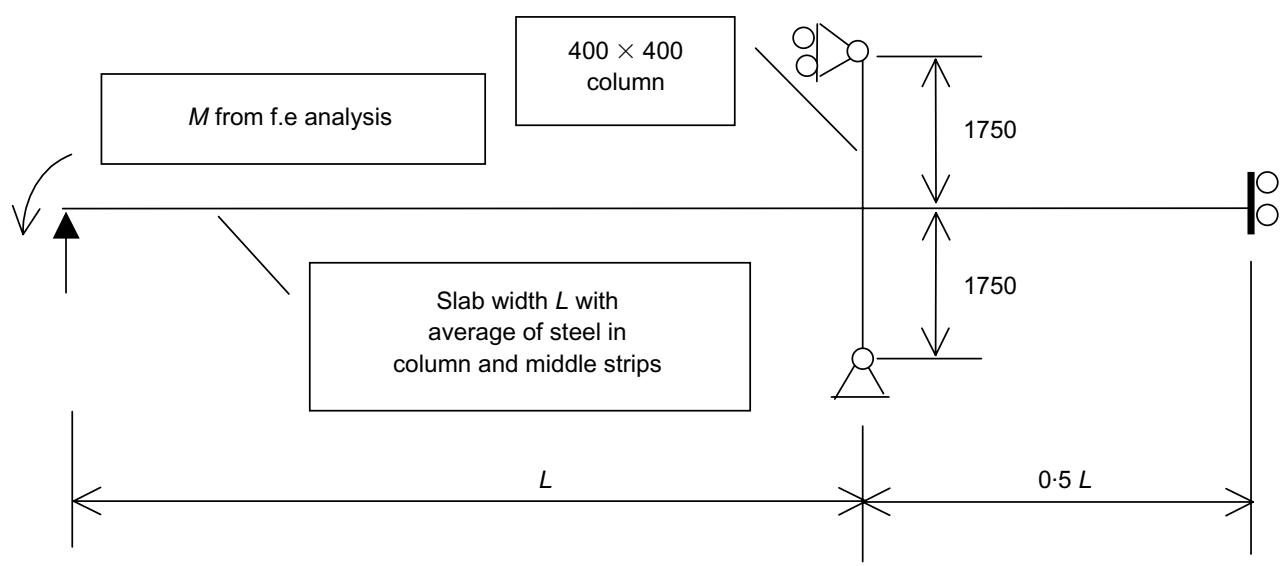

Fig. 10. Equivalent frame used to determine deflection multipliers in flat slabs 
compares deflection multipliers from NLFE analysis and equivalent subframes with edge columns ('Beam e.col' in Fig. 11) for long-term effective elastic moduli in the columns of 10 and $20 \mathrm{kN} / \mathrm{mm}^{2}$. Sub-frame analysis gives unreliable estimates of edge column moments and, consequently, deflection multipliers since it overestimates the influence of column stiffness due to its failure to model the flexibility of slab-column connections. The solution (see 'Beam' in Fig. 11) was to estimate edge column moments in an elastic finite element analysis. This required a two-stage procedure. In the first stage, instantaneous deflections were derived for the sub-frame shown in Fig. 10 using the elastic modulus in the slab at striking for both the slab and internal column. The edge column moment used in the sub-frame analysis was derived in an elastic finite element analysis with plate elements using the same elastic modulus as in the sub-frame analysis. In the second stage, long-term deflections were calculated in the sub-frame in Fig. 10 using non-linear cracked section analysis. The edge column moment used in the sub-frame analysis was derived in an elastic finite element analysis in which the elastic modulus of the slab was reduced iteratively until the deflection multiplier in the corner bay equalled that given by the sub-frame analysis. The required reduction in slab stiffness is slightly greater than the deflection multiplier since the long-term reduction in stiffness is less in the column than in the slab.

Deflection multipliers, derived from NLFE analysis, are slightly less for external than corner panels since moments perpendicular to the slab edge are less in external panels. It is not realistic to determine separate multipliers for corner, external and internal panels from the subframe in Fig. 10 since deflections in internal panels are overly sensitive to conditions in the external spans. Consequently, the subframe gives best estimates of deflection multipliers for corner panels. Therefore, the edge column moment was taken as twice the corner column moment in the subframe analysis. Long-term deflections were calculated by multiplying instantaneous deflections from the finite element plate analysis by the overall deflection multiplier $C\left(1+\phi_{\text {eff }}\right)$. Alternatively, long-term deflections can be derived from a linear elastic finite element plate analysis in which the reduced elastic modulus $E_{\text {cstrike }} /\left[C\left(1+\phi_{\text {eff }}\right)\right]$ is used in both the slab and columns. Deflections should not be taken from the elastic finite element analysis used to estimate the long-term corner column moment because this analysis gives different (and incorrect) multipliers for the external and internal bays. Actual and predicted deflections multipliers are compared in Figs 11-16 which show the effect on deflection multipliers $C$ of varying column size and stiffness, concrete strength, imposed load $w_{i}$, reinforcement area $A_{\text {sprov }} / A_{\text {sreq }}$, slab thickness and span. Figs 11-16 show that the proposed method for estimating deflection multipliers ('Beam' in Figs 11-16) gives reasonable results (within 10\% for

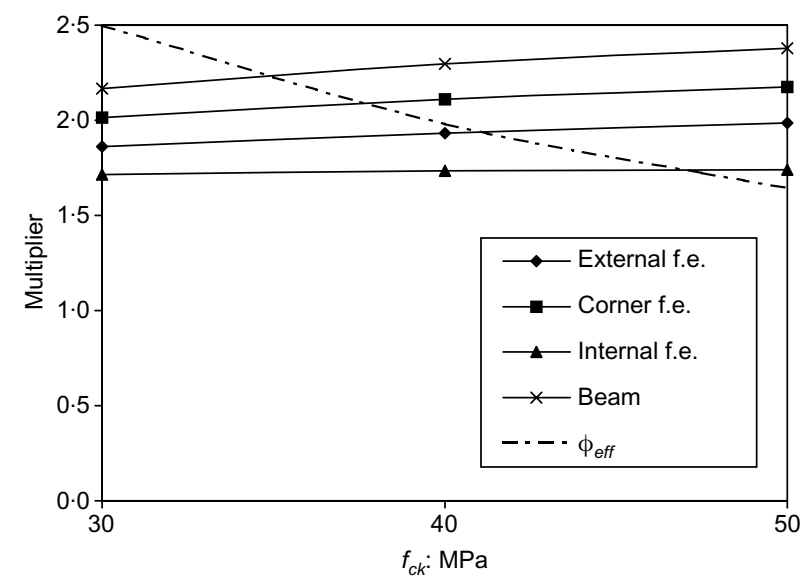

Fig. 12. Deflection multipliers vs. $f_{c k}$

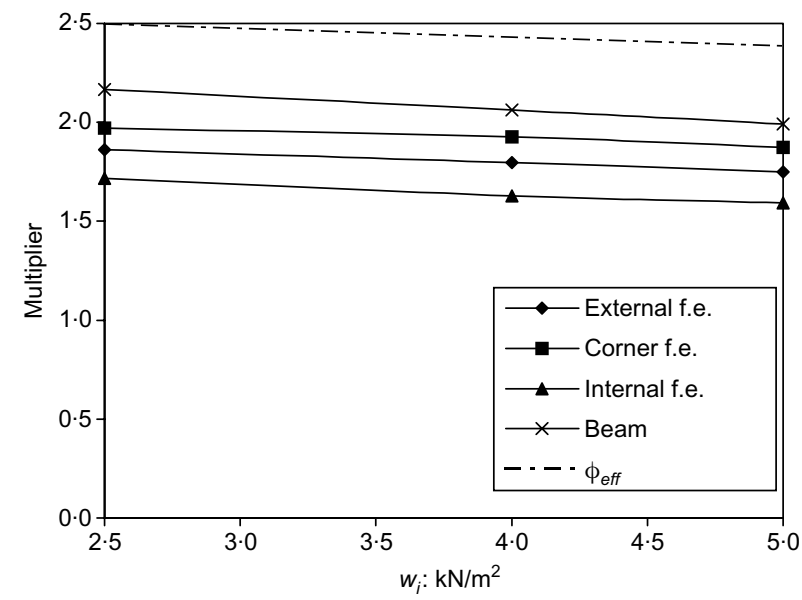

Fig. 13. Multipliers vs. $w_{i}$ for deflections under $w_{\text {perm }}$

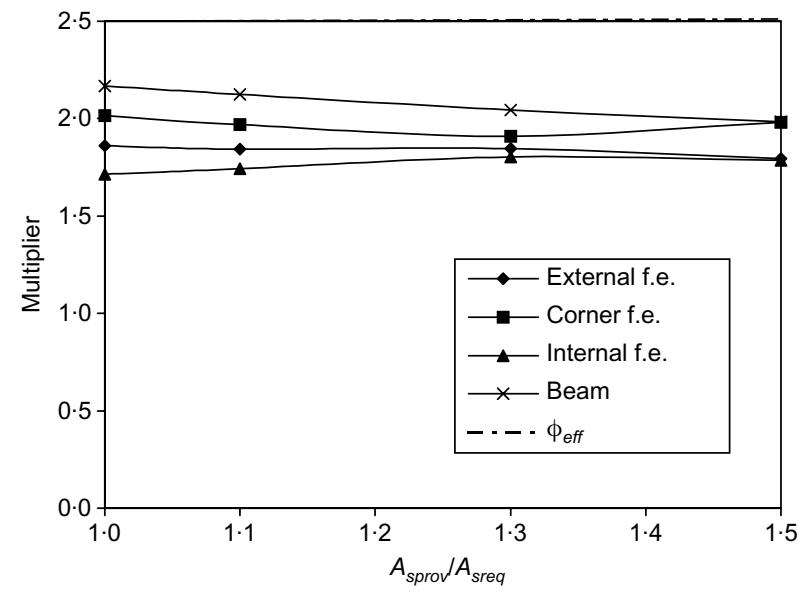

Fig. 14. Deflection multipliers vs. $A_{\text {sprov }} / A_{\text {sreq }}$

the corner panels) in all cases. It is interesting to note that the deflection multipliers due to cracking and shrinkage are close to 2 in Figs 11-16. Figure 17 shows that multipliers are almost independent of strik- 




Fig. 15. Deflection multipliers vs. slab thickness

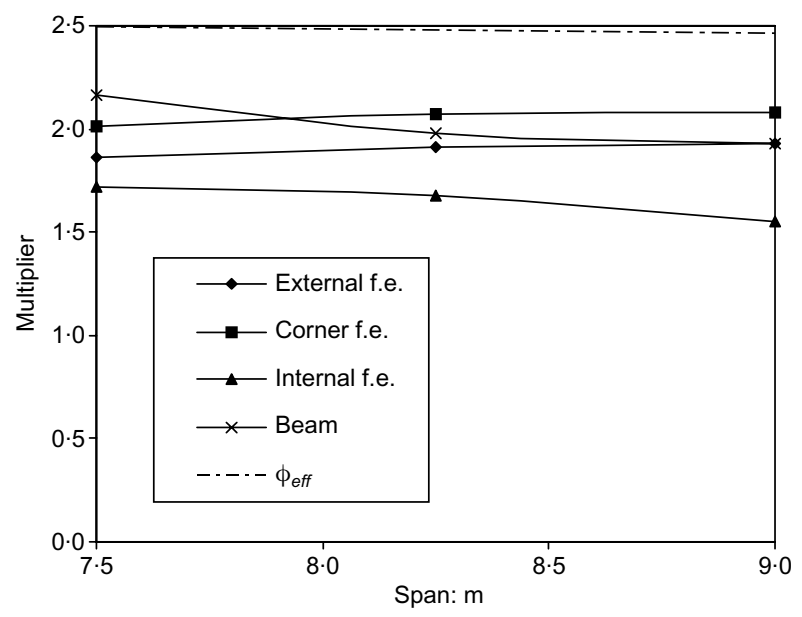

Fig. 16. Deflection multipliers vs. span

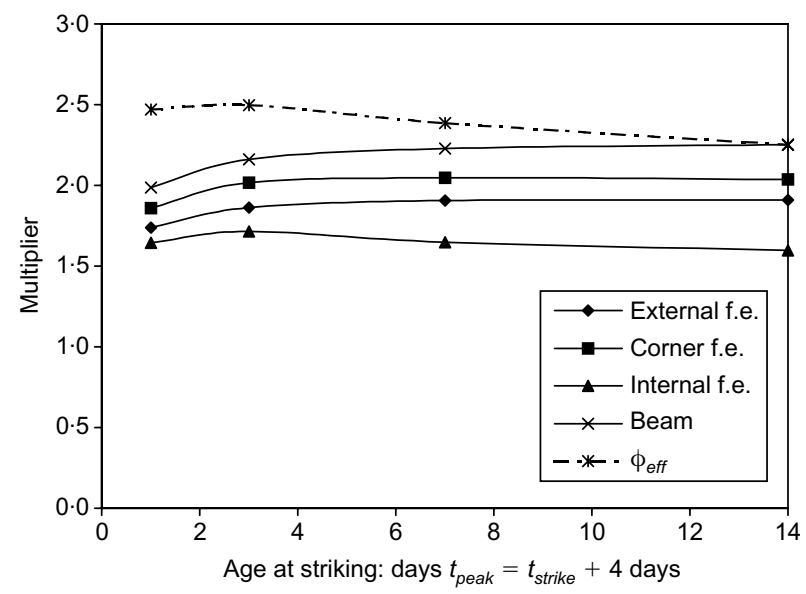

Fig. 17. Deflection multipliers vs. striking time $(h=265 \mathrm{~mm})$

ing time if the peak construction load is applied 4 days after striking. In reality, deflections in cracked members are not inversely proportional to $E_{\text {cstrike }} /\left(1+\phi_{\text {eff }}\right)$ as suggested by Figs $11-17$ in which the peak construc- tion load was applied 4 days after striking. Deflections reduce marginally, for a given age at $w_{\text {peak }}$, if the time between striking and peak construction load is less than 4 days but deflection multipliers increase since $E_{\text {cstrike }}$ increases. The effect of increasing the time between striking and peak construction load is shown in Fig. 18 where deflection multipliers are plotted against the age at peak construction load for a $265 \mathrm{~mm}$ thick slab struck at 2 days. Fig. 18 shows that deflection multipliers reduce as the time between striking and peak construction load increases. Fig. 19 shows that deflection multipliers increase to approximately 2 for the slabs in Fig. 18 if instantaneous deflections are calculated with $E_{\text {cstrike }}=E_{c(\text { peak-4 })}$ where $E_{c(\text { peak-4) }}$ is the concrete elastic modulus 4 days before application of $w_{\text {peak }}$ as assumed in Figs 11-17. The creep coefficients used in the derivation of Fig. 19 were based on the actual age at striking of 2 days. Elsewhere, ${ }^{3}$ it is shown that deflections are more sensitive to the age of application of $w_{\text {peak }}$ than the age at striking unless $K_{\text {strike }}$ is critical. In practice, $K_{\text {peak }}$ is seldom critical unless slabs are struck within 1 day. This suggests the follow-

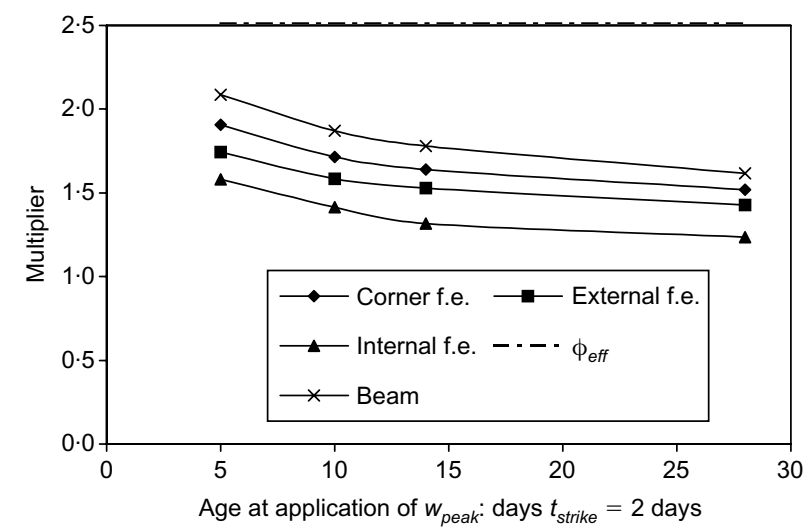

Fig. 18. Deflection multipliers vs. age at peak construction load $(h=265 \mathrm{~mm})$

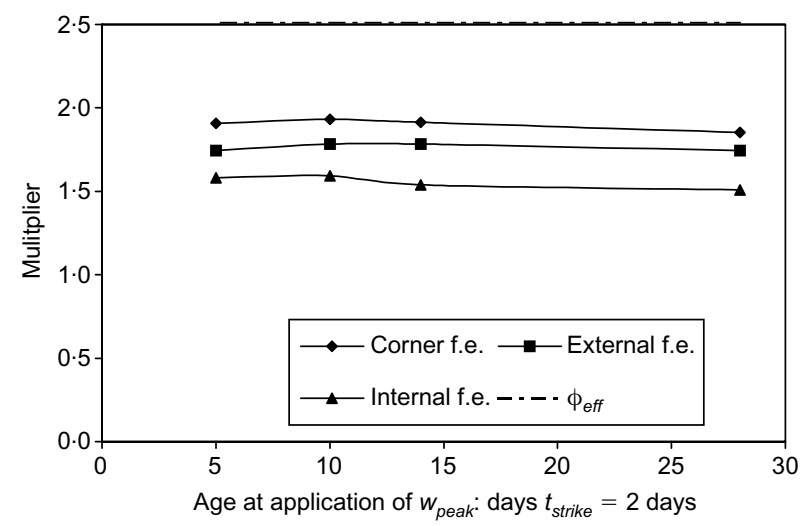

Fig. 19. Revised deflection multipliers vs. age at peak construction load $(h=265 \mathrm{~mm})$

Magazine of Concrete Research, 2003, 55, No. 2 
ing simplified method for estimating long-term deflections in flat slabs

$$
a=2\left(1+\phi_{\text {eff }}\right) a_{i}
$$

where $a_{i}$ is the instantaneous elastic deflection from a finite element analysis using the concrete elastic modulus 4 days before application of $w_{\text {peak }}$ and $\phi_{\text {eff }}$ is derived with equation (10) using the actual load history. Equation (12) is equivalent to calculating deflections with an elastic modulus equal to $0 \cdot 5 E_{\text {cstrike }} /\left(1+\phi_{\text {eff }}\right)$ in both the slab and columns where $E_{\text {cstrike }}=E_{c(\text { peak-4) }}$. In practice, designers find it more convenient to use 28 day properties for concrete. In this case, it is usually conservative to use a reduced elastic modulus of $0.4 E_{c m 28} /\left(1+\phi_{E C 2}\left(t_{0}=28, t_{\infty}\right)\right)$ which corresponds to the load history used in Figs 11-16. The corresponding reduced elastic moduli are almost independent of slab thickness and equal $4 \cdot 0,5 \cdot 0$ and $6.0 \mathrm{GPa}$ for a $250 \mathrm{~mm}$ thick slab with $\mathrm{C} 30, \mathrm{C} 40$ and $\mathrm{C} 50$ concrete (cylinder strengths) respectively.

\section{Increment in deflection due to partitions and quasi- permanent load}

Designers may need to evaluate the increment in deflection due to finishes and the permanent component of the design imposed load. The increment in deflection can be evaluated with the equivalent subframe using the procedure described by the author previously. ${ }^{3}$ Alternatively, parametric studies suggest that typically 65 to $70 \%$ of the final deflection under selfweight occurs within the first two months after striking (if deflections are governed by cracking during construction as is usual) assuming the relative humidity (RH) reduces from $80 \%$ during construction to $50 \%$ in the finished building. Similar ratios (see Table 2) of early ( 35 to 70 days) to long-term (800 days) deflections were measured in the corner bays of the Cardington $^{2,4}$ in situ building which were not loaded. It is estimated that the 800 day deflections in the Cardington slabs were around $80 \%$ of the deflections that would have developed at 10000 days if the RH had been $50 \%$. Consequently, it is recommended that increments in deflection $\Delta a$ due to finishes and quasi-permanent load are conservatively estimated as

$$
\Delta a=a_{\text {perm }}\left(1-0.55 w_{\text {self }} / w_{\text {perm }}\right)
$$

where $a_{\text {perm }}$ is given by equation (12). The coefficient of 0.55 in equation (13) was derived by scaling the average of the deflection ratios measured at Cardington (see Table 2) by 0.8 to take into account the increase in deflection from 800 days and a reduction in $\mathrm{RH}$ to $50 \%$ in the finished building.

\section{Derivation of deflections in the Cardington slabs with multipliers}

Equation (12) was used to estimate deflections measured in the Cardington in situ building ${ }^{2,4}$ at 800 days. Ten thousand day deflections were also estimated using equation (12) and the subframe shown in Fig. 10 for a loading case where all panels were loaded with $w_{\text {perm }}=9 \mathrm{kN} / \mathrm{m}^{2}$ at 28 days. The relative humidity was taken as $50 \%$ rather than $70 \%$ at Cardington. Actual concrete strengths, ages at striking and application of peak construction load and peak construction loads were used in the analysis. The 10000 day deflections were compared with deflections calculated using Hossain's finite element program. ${ }^{2,10}$ The results are given in Table 2 that shows equation (12) gives good

\begin{tabular}{|c|c|c|c|c|c|c|c|}
\hline Floor & & 1 & 2 & 3 & 4 & 5 & 6 \\
\hline \multicolumn{8}{|c|}{$\% 800$ day deflection measured in corner bays $t_{1}$ days after striking } \\
\hline $\begin{array}{l}\text { Time } t_{1} \text { at } m \\
\% 800 \text { day de }\end{array}$ & $\begin{array}{l}\text { nt (days) } \\
\text { at } t_{1}\end{array}$ & $\begin{array}{l}49 \\
0 \cdot 71\end{array}$ & $\begin{array}{l}53 \\
0 \cdot 56\end{array}$ & $\begin{array}{l}75 \\
0 \cdot 70\end{array}$ & $\begin{array}{l}62 \\
0 \cdot 73\end{array}$ & $\begin{array}{l}49 \\
0.66\end{array}$ & $\begin{array}{l}35 \\
0 \cdot 74\end{array}$ \\
\hline \multicolumn{8}{|c|}{ Deflections at 800 days $(\mathrm{mm})$ corner panels $w_{p c r m}=6 \mathrm{kN} / \mathrm{m}^{2} ;$ external panels $w_{p c r m}=9 \mathrm{kN} / \mathrm{m}^{2}$} \\
\hline \multirow{2}{*}{\multicolumn{2}{|c|}{$\begin{array}{c}E_{c} /\left(1+\phi_{\text {eff }}\right) \text { Corner } \\
E_{c} /\left(1+\phi_{\text {eff }}\right) \text { External }\end{array}$}} & $13 \cdot 10$ & $12 \cdot 20$ & $11 \cdot 41$ & $13 \cdot 02$ & $10 \cdot 92$ & $11 \cdot 33$ \\
\hline & & $15 \cdot 62$ & 14.94 & $13 \cdot 66$ & $15 \cdot 51$ & $13 \cdot 10$ & $13 \cdot 40$ \\
\hline Measured* & Corner & $23 \cdot 46$ & $24 \cdot 07$ & $27 \cdot 11$ & $25 \cdot 22$ & $26 \cdot 27$ & $27 \cdot 97$ \\
\hline Equation 12 & Corner & $25 \cdot 42$ & $27 \cdot 30$ & $29 \cdot 18$ & $25 \cdot 58$ & $30 \cdot 50$ & $29 \cdot 40$ \\
\hline Measured* & External & $18 \cdot 84$ & $23 \cdot 62$ & $26 \cdot 37$ & $21 \cdot 06$ & $25 \cdot 06$ & $27 \cdot 19$ \\
\hline Equation 12 & External & $25 \cdot 28$ & $26 \cdot 45$ & $28 \cdot 92$ & $25 \cdot 47$ & $30 \cdot 16$ & $29 \cdot 48$ \\
\hline \multicolumn{8}{|c|}{ Deflections at 10,000 days $(\mathrm{mm}) w_{p c r m}=9 \mathrm{kN} / \mathrm{m}^{2}$} \\
\hline \multicolumn{2}{|c|}{$E_{c} /\left(1+\phi_{e f f}\right)(\mathrm{GPa})$} & $11 \cdot 87$ & $11 \cdot 27$ & $10 \cdot 21$ & $11 \cdot 85$ & $9 \cdot 69$ & $9 \cdot 91$ \\
\hline NLFE & Corner & $38 \cdot 11$ & $42 \cdot 32$ & $42 \cdot 95$ & $39 \cdot 85$ & $49 \cdot 50$ & $45 \cdot 35$ \\
\hline Beam & Corner & $39 \cdot 51$ & $42 \cdot 23$ & $44 \cdot 37$ & $39 \cdot 32$ & $46 \cdot 35$ & $49 \cdot 90$ \\
\hline Equation 12 & Corner & $43 \cdot 36$ & $45 \cdot 65$ & $50 \cdot 40$ & $43 \cdot 42$ & $53 \cdot 08$ & 51.91 \\
\hline NLFE & External & $29 \cdot 40$ & $32 \cdot 28$ & $33 \cdot 21$ & $29 \cdot 39$ & $37 \cdot 14$ & $34 \cdot 10$ \\
\hline Beam & External & $30 \cdot 33$ & $32 \cdot 42$ & $34 \cdot 06$ & $30 \cdot 19$ & $35 \cdot 58$ & $38 \cdot 31$ \\
\hline Equation 12 & External & $33 \cdot 29$ & $35 \cdot 05$ & $38 \cdot 69$ & $33 \cdot 34$ & $40 \cdot 75$ & $39 \cdot 85$ \\
\hline
\end{tabular}

Table 2. Measured and predicted deflections in Cardington slabs

* Maximum value. 
estimates of the deflections measured at 800 days. Both equation (12) and the subframe analysis give similar deflections to NLFE analysis in the corner and external panels for which multipliers were similar due to the openings for stairs in the Cardington slabs. Table 2 also gives the values of $E_{\text {cstrike }} /\left(1+\phi_{\text {eff }}\right)$ used in equation (12).

\section{Conclusion}

In practice, slabs are often designed using elastic finite element plate analysis. Consequently, simplified methods are required to predict long-term deflections in cracked slabs from elastic deflections in uncracked slabs. This article shows that long-term deflections can be estimated by increasing elastic deflections by multipliers derived from the analysis of equivalent beam strips with the average of the reinforcement in the column and middle strips. Multipliers are significantly overestimated if columns are not modelled since cracking is overestimated in the span. The restraining effect of columns usually increases with time since the slab stiffness reduces more than the column stiffness. Equivalent frame analysis tends to overestimate edge column moments. Therefore, it is recommended that edge column moments are derived for the beam strip analysis in a linked elastic finite element plate analysis in which the slab stiffness is reduced iteratively until the deflection multiplier in the corner panel equals that given by the beam strip analysis. In practice, designers have little knowledge of $(a)$ concrete properties at striking and application of peak construction loads and $(b)$ reinforcement arrangement when slab thicknesses are finalised and deflections estimated. Therefore, it is questionable whether it is appropriate to use sophisticated NLFE analysis or equivalent beam strips to estimate deflections in design. This article proposes a very simple method for estimating deflections in flat slabs that does not require knowledge of the reinforcement provided. The method has been calibrated using NLFE analysis taking construction loading into account and gives good estimates of deflections in the Cardington slabs. It is proposed that long-term deflections in flat slabs are estimated from an elastic finite element analysis with plate elements using an equivalent elastic modulus equal to $0 \cdot 5 E_{\text {cstrike }} /\left(1+\phi_{\text {eff }}\right)$ in both the slab and columns where $\phi_{\text {eff }}$ is defined in equation (10) and $E_{c s t r i k e}=E_{c(\text { peak-4) }}$. More conveniently, it is usually conservative to calculate long-term deflections in an elastic analysis finite element analysis with reduced elastic moduli of $4 \cdot 0,5 \cdot 0$ and $6 \cdot 0 \mathrm{GPa}$ for $\mathrm{C} 30, \mathrm{C} 40$ and $\mathrm{C} 50$ concrete (cylinder strengths) respectively.

\section{References}

1. Whittle R. T. Design of reinforced concrete flat slabs to BS 8110 (Report 110 Revised Edition 1994), CIRIA Report R110, 1994.

2. Hossain T. R. and Vollum R. L. Prediction of slab deflections and validation against Cardington data. Structures and Buildings, 2002, 152, No. 3, 235-248.

3. Vollum R. L. and Hossain T. R. Are existing span to depth rules conservative for flat slabs? Magazine of Concrete Research, 2002, 54, No. 6, 411-421.

4. Vollum R. L., Moss R. M. and Hossain T. R. Slab deflections in the Cardington in-situ concrete building. Magazine of Concrete Research, 2002, 54, No. 1, 23-24.

5. Comite Euro-International Du Beton. CEB-FIP Model Code for Concrete Structures, Thomas Telford, London, 1990.

6. EUROPEAN STANDARD. Design of concrete structures, Part 1, General rules and rules for buildings, CEN, Eurocode 2, prEN 1992-1, 2001

7. BRITISH STANDARDS InSTITUTION. Structural use of concrete; Part 1: 1997 Code of practice for design and construction, BSI, London, BS 8110.

8. BEEBY A. W. Early striking of formwork and forces in backprops. Construction Research Communications Report BR 394, 2000.

9. WEBSTER R. The Influence of serviceability on the economic design of concrete structures, 39/3/536 cc 1824 Discussion report No. 2, BCA, July 2000 .

10. VOLLUM R. L. The influence of shrinkage on loss of tension stiffening. Magazine of Concrete Research, 2002, 54, No. 4, 273 282.

Discussion contributors on this paper should reach the editor by 1 October 2003 